\title{
Pharmacological evaluation of Prosopis ruscifolia extract on lipid profile in hyperglycemic and hyperlipidemic mice
}

\author{
Juan R. Centurión, Elena M. G. Diarte, Antonia Galeano, María S. Soverina, Wilfrido Arrúa, María L. Kennedy (D), \\ Miguel A. Campuzano-Bublitz* iD \\ Departamento de Farmacología, Facultad de Ciencias Químicas, Universidad Nacional de Asunción, San Lorenzo, Paraguay.
}

\section{ARTICLE INFO \\ Article history: \\ Received on: April 29, 2021 \\ Accepted on: July 02, 2021 \\ Available online: November 10, 2021}

Key words:

Lipid profile, glycemia, diabetic dyslipidemia, tyloxapol, alloxan

\begin{abstract}
Diabetes is a serious chronic pathology, with long-term effects including damage to blood vessels or diabetic dyslipidemia. Diabetic dyslipidemia is characterized by increasing concentrations of low-density triglycerides and lipoproteins and a decrease in high-density lipoproteins HDL-cholesterol (HDL-c). This study aimed to evaluate the effect of Prosopis ruscifolia on lipid profile in albino Swiss mice with hyperglycemia and hyperlipidemia. Hyperglycemia was induced by alloxan and the animals were orally treated with $\operatorname{Pr}(50,100$, and $200 \mathrm{mg} / \mathrm{kg})$ for 45 days. Hyperlipidemia was induced with tyloxapol and the animals were treated with $\operatorname{Pr}(50,100$, and $200 \mathrm{mg} / \mathrm{kg}$ ). In hyperglycemic animals treated with $100 \mathrm{mg} / \mathrm{kg}$, there was a decrease in the concentration of cholesterol, a decrease in the concentration of triglycerides, and an increase in HDL-c at the end of treatment compared to untreated hyperglycemic animals. In mice with hyperlipidemia treated with 50 and $100 \mathrm{mg} / \mathrm{kg}$ of $\mathrm{Pr}$, serum cholesterol and triglyceride concentration were reduced. HDL-c increased in animals treated with $\operatorname{Pr} 50$, 100 , and $200 \mathrm{mg} / \mathrm{kg}$ compared to untreated animals. It was observed that the administration of $P$. ruscifolia in hyperglycemic and hyperlipidemic animals had a favorable effect on the lipid profile.
\end{abstract}

\section{INTRODUCTION}

Diabetes is a serious chronic disease and a global health problem that affects more than 400 million people. Each year, over 1.6 million deaths occur as a result of diabetes or associated pathologies, such as cardiovascular diseases, deterioration of kidney function, dyslipidemia, and others [1]. Diabetes is a metabolic disorder that affects different parts of the body, with short- and longterm consequences, such as ketoacidosis due to hyperglycemia or diabetic coma. Chronic exposure to hyperglycemia causes an imbalance in cellular homeostasis which then leads to damaged blood vessels, among other effects [2,3]. All this implies a great expense in public health systems $[1,4]$.

Cardiovascular disorders in diabetic patients involve atherosclerosis, which causes broken atherogenic plaques to pass into the circulation to obstruct a vessel and induce myocardial

\footnotetext{
*Corresponding Author

Miguel A. Campuzano-Bublitz, Departamento de Farmacología, Facultad de Ciencias Quimicas, Universidad Nacional de Asunción, San Lorenzo, Paraguay.E-mail: mbublitz@qui.una.py
}

infarction or stroke [5]. This constitutes the main cause of morbidity and mortality in people with diabetes, and one of the predominant risk factors is dyslipidemia. These patients generally present a pattern characterized by high concentrations of triglycerides and low-density lipoproteins (LDL) LDL-cholesterol (LDL-c) and a reduction in high-density lipoproteins (HDL) HDL-cholesterol (HDL-c) called atherogenic dyslipidemia [2,5].

Type 2 diabetes mellitus (T2D) is mostly associated with being overweight or obese. Patients who suffer from it, in addition to presenting altered glucose metabolism, also suffer from alterations in lipid metabolism. Obesity, characterized by excessive accumulation of abdominal and visceral fat, is associated with insulin resistance and hyperinsulinemia. Due to this insulin resistance, there is a greater release of free fatty acids from adipocytes, which in the liver induce an increase in the synthesis of triglycerides and stimulate the production of apolipoprotein B. An increase in the production of triglyceride-rich very low-density lipoprotein (VLDL) particles is also observed, which increases the concentration of triglycerides in the blood $[5,6]$. This increase in VLDL causes an increase in the hepatic protein cholesterol ester transfer protein, which transfers cholesteryl esters from HDL to 
apolipoprotein B containing particles VLDL and LDL, reducing HDL concentration. There is transfer of triglyceride in the opposite direction such that cholesteryl ester-depleted HDL and LDL become triglyceride-rich. Levels of small dense LDL are thus increased $[7,8]$.

Treatment of diabetes includes changes in lifestyle, diet, increased physical activity, and decreased carbohydrate intake. Additionally, patients with T2D are treated with an oral hypoglycemic drug. Historically, herbal medicines have also been utilized in the treatment and prevention of diseases such as diabetes [9]. Several medicinal plants have been shown to be effective in different stages of diabetes.

Previously, this research group determined the hypoglycemic effect of Prosopis ruscifolia in Wistar rats and in Swiss albino mice, in addition to a favorable effect on the cardiovascular risk index and atherogenic risk index in hyperglycemic mice $[10,11]$. This medicinal plant was also demonstrated to protect liver and kidney from the damage induced by acetaminophen and gentamicin, respectively [12]. Other species of Prosopis, such as Prosopis farcta, demonstrated a favorable effect on the decrease of glycemia and blood lipid concentrations in models of diabetic animals. Prosopis cineraria also proved to have favorable effects on glycemia and lipidemia [13-15]. This work reports the effect of the $P$. ruscifolia extract on the lipid profile in a mouse model with experimental hyperglycemia by alloxan in an observation period of 45 days and in hyperlipidemic mice by tyloxapol.

\section{MATERIAL AND METHODS}

\subsection{Plant Material and Extract}

Aerial parts of $P$. ruscifolia Griseb (Fabaceae), named locally viñal, were collected in Teniente Irala Fernández, Chaco, Paraguay, identified by experts, and deposited in the FCQ herbarium (Degen 4581 herbarium specimen). First, the extract of the leaves was obtained by refluxing with ethanol, then preserved in a desiccator, and resuspended in water for use [10].

\subsection{Drugs and Reagents}

Ethanol was purchased locally and distilled before use. The lipid profiling kits used were from the HUMAN brand. Alloxan and Triton WR-1339 (tyloxapol) were from Sigma-Aldrich Co. (St. Louis, MO). Blood glucose test strips were from HUMAN.

\subsection{Experimental Animals}

Swiss albino mice, male and female, 10-12 weeks old, weighing 25-35 g were obtained from the Bioterium of the Department of Pharmacology of the Facultad de Ciencias Químicas, UNA. They were kept in polypropylene boxes in the Bioterium, with a light/dark cycle of $12 / 12$ hours, in a controlled environment with a temperature of $20^{\circ} \mathrm{C}-24^{\circ} \mathrm{C}$ and relative humidity of the environment of $60 \pm 5 \%$. The animals received food ration and water ad libitum.

\subsection{Induction of Hyperglycemia by Alloxan}

Male animals were selected and randomly assigned into eight groups $(n=6)$. Four groups were induced to hyperglycemia by alloxan monohydrate (150 mg/kg, i.p.), after having been deprived of food for 18 hours. After induction, they received free food and a 10\% glucose solution overnight. One week after induction, the fasting glucose concentration was determined. Blood from the tail vein was obtained for fasting blood glucose measurement with a glucometer. Mice with a glycemia greater than $180 \mathrm{mg} / \mathrm{dl}$ were considered hyperglycemic and treated for 45 days with water (Hv), $50(\mathrm{HPr}$ 50), 100 (HPr 100), or $200 \mathrm{mg} / \mathrm{kg}$ (HPr 200) of the P. ruscifolia extract. Additionally, four groups of normoglycemic animals were treated for 45 days with water (Nv), 50 (NPr 50), 100 (NPr 100), or $200 \mathrm{mg} / \mathrm{kg}$ (NHPr 200) of the P. ruscifolia extract. On day 46, after 6 hours of fasting, the animals were anesthetized with an i.p. injection of sodium pentobarbital $(40 \mathrm{mg} / \mathrm{kg}$ ) to obtain blood through cardiac puncture. Thus, the blood of each animal was obtained, and the obtained blood was incubated to promote the formation of the clot and the separation of the serum by centrifugation of the samples. Next, this serum was fractionated to measure the lipid profile, according to instructions for HUMAN reagents. The glycemia of the animals was monitored every 15 days $[16,17]$. Very low-density lipoprotein cholesterol (VLDL-c) and LDL-c were calculated using Friedewald's equation. VLDL-c $=$ serum triglyceride $/ 5 ; \mathrm{LDL}=\mathrm{TC}$ - VLDL-c - HDL-c. Results were expressed in mg/dl. Atherogenic index (AI) was calculated as LDL-c/HDL-c and coronary risk index (CRI) was calculated as TC/HDL-c.

\subsection{Induction of Hyperlipidemia in Male and Female Mice}

To induce elevation of cholesterol and triglycerides in male and female Swiss albino mice, i.p. injection was used. Tyloxapol (Triton WR-1339) was injected in doses of $350-400 \mathrm{mg} / \mathrm{kg}$, according to sex. Animals were randomly assigned to one of eight work groups $(n=6)$. Four groups of female hyperlipidemic animals received water (Hv), 50 (HPr 50), 100 (HPr 100), or $200 \mathrm{mg} / \mathrm{kg}$ (HPr 200) of the P. ruscifolia extract, 48, 24, and 1 hours before injection of tyloxapol, and 24 hours after induction, the animals were anesthetized with an i.p. injection of sodium pentobarbital $(40 \mathrm{mg} / \mathrm{kg})$ to obtain blood through cardiac puncture [16]. Similarly, four groups of female animals with normal lipemia received water $(\mathrm{Nv}), 50(\mathrm{NPr} 50), 100(\mathrm{NPr} 100)$, or $200 \mathrm{mg} / \mathrm{kg}$ (NHPr 200) of the extract of P. ruscifolia, 48, 24, and 1 hours before tyloxapol injection, and 24 hours after induction, blood was obtained by the same procedure already mentioned. The same procedure was performed with four groups of hyperlipidemic male animals with tyloxapol and four normolipemic animals. The extraction of samples from the mice was carried out after 6 hours of fasting in all cases.

\subsection{Ethical Issues}

The animals were considered as biological reagents; therefore, the work was carried out in accordance with the standards established by the Ethics Committee of the European Commission. The handling of the biological reagents was carried out by standardized procedures in accordance with the Principles of Laboratory Animal Care. The minimum number of animals required for each trial was used, and the shortest observation duration was required to obtain consistent data. Each animal was employed once [18]. The protocol was submitted for consideration by the Research Ethics Committee of the Facultad de Ciencias Químicas, UNA, and approved (CEI 470/19). 


\subsection{Statistical Analysis of the Results}

The GraphPad Prisma 7.0 program was used and the data from the various groups were expressed as means \pm standard deviation. The statistical analysis used was one-way analysis of variance (ANOVA), followed by Tukey's multiple comparison test; a level of $p<0.05$ was considered statistically significant.

\section{RESULTS AND DISCUSSION}

First, the effect of $P$. ruscifolia extract on the glycemia of normoand hyperglycemic mice was verified, after chronic treatment for 45 days in eight groups of male mice $(n=6)$ : $\mathrm{Nv}$ (normoglycemic treated with vehicle, water); NPr 50, NPr 100, and NPr $200 \mathrm{mg} /$ $\mathrm{kg}$ (normoglycemic treated with the extract, 50, 100, and $200 \mathrm{mg} /$ $\mathrm{kg}$, resp.); Hv (hyperglycemic, vehicle-treated water); $\mathrm{HPr} 50$, HPr 100, and HPr $200 \mathrm{mg} / \mathrm{kg}$ (hyperglycemic treated with the extract, 50, 100, and $200 \mathrm{mg} / \mathrm{kg}$, resp.). A statistically significant difference was established between the initial glycemia of the animals in group $\mathrm{Hv}$ and those in group $\mathrm{Nv}$, which was maintained during the 45 days of treatment. In addition, it was found that the glycemia of the animals in the Nv group remained unchanged and the glycemia of the hyperglycemic animals, Hv, remained high throughout the treatment (Table 1).

\subsection{Effect of $P$. ruscifolia on Normal and Hyperglycemic Animals the Lipid Profile}

In all the groups of animals with normal glycemia, it was observed that there was no significant difference in any parameter of the lipid profile between those that received vehicle or the extract. The hyperglycemic animals that received water presented a significant difference in the cholesterol level with respect to the normoglycemic (Nv: $103.1 \mathrm{mg} / \mathrm{dl} \pm 8.4$; Hv: $130.5 \mathrm{mg} / \mathrm{dl} \pm 20.03, p$ $<0.001)$, and in the groups of hyperglycemic animals treated with $100 \mathrm{mg} / \mathrm{kg}$ (HPr 100: $108.7 \mathrm{mg} / \mathrm{dl} \pm 5.78, p<0.1$ ), the cholesterol level was significantly different with respect to the control group Hv. In addition, a nonsignificant reduction was observed in the group HPr 50. So, a certain hypocholesterolemic effect of the extract in hyperglycemic animals was demonstrated (Fig. 1A).

In the group of $\mathrm{Hv}$ animals $(113.5 \mathrm{mg} / \mathrm{dl} \pm 39.8, p<0.01)$, the triglyceride level was significantly higher compared to the groups of $\mathrm{Nv}$ animals $(70.5 \mathrm{mg} / \mathrm{dl} \pm 11.5)$. The animals in the HPr 50

Table 1: Effect after 45 days oral treatment of normo- and hyperglycemic mice with $P$. ruscifolia leaves extract.

\begin{tabular}{ccc} 
Group & Initial glycemia & Final glycemia \\
Nv & $153.0 \pm 17.30$ & $105.2 \pm 13.51$ \\
NPr 50 & $167.2 \pm 17.72$ & $126.0 \pm 17.74$ \\
NPr 100 & $157.7 \pm 21.89$ & $142.8 \pm 12.56$ \\
NPr 200 & $179.5+/-20.47$ & $128.5 \pm 22.34$ \\
Hv & $432.0 \pm 22.14$ & $278.3 \pm 48.87 * * *$ \\
HPr 50 & $448.5 \pm 32.27$ & $341.0 \pm 61.93 * * * *$ \\
HPr 100 & $479.3 \pm 8.43$ & $395.3 \pm 31.87 * * *$ \\
HPr 200 & $578.0+/-15.89$ & No data \\
\hline
\end{tabular}

Data are expressed as mean $\pm \mathrm{SD}$, after one-way ANOVA, Tukey's posttest. $* * * p<0.001 ; * * * * p<0.0001$ en relación con Nv.
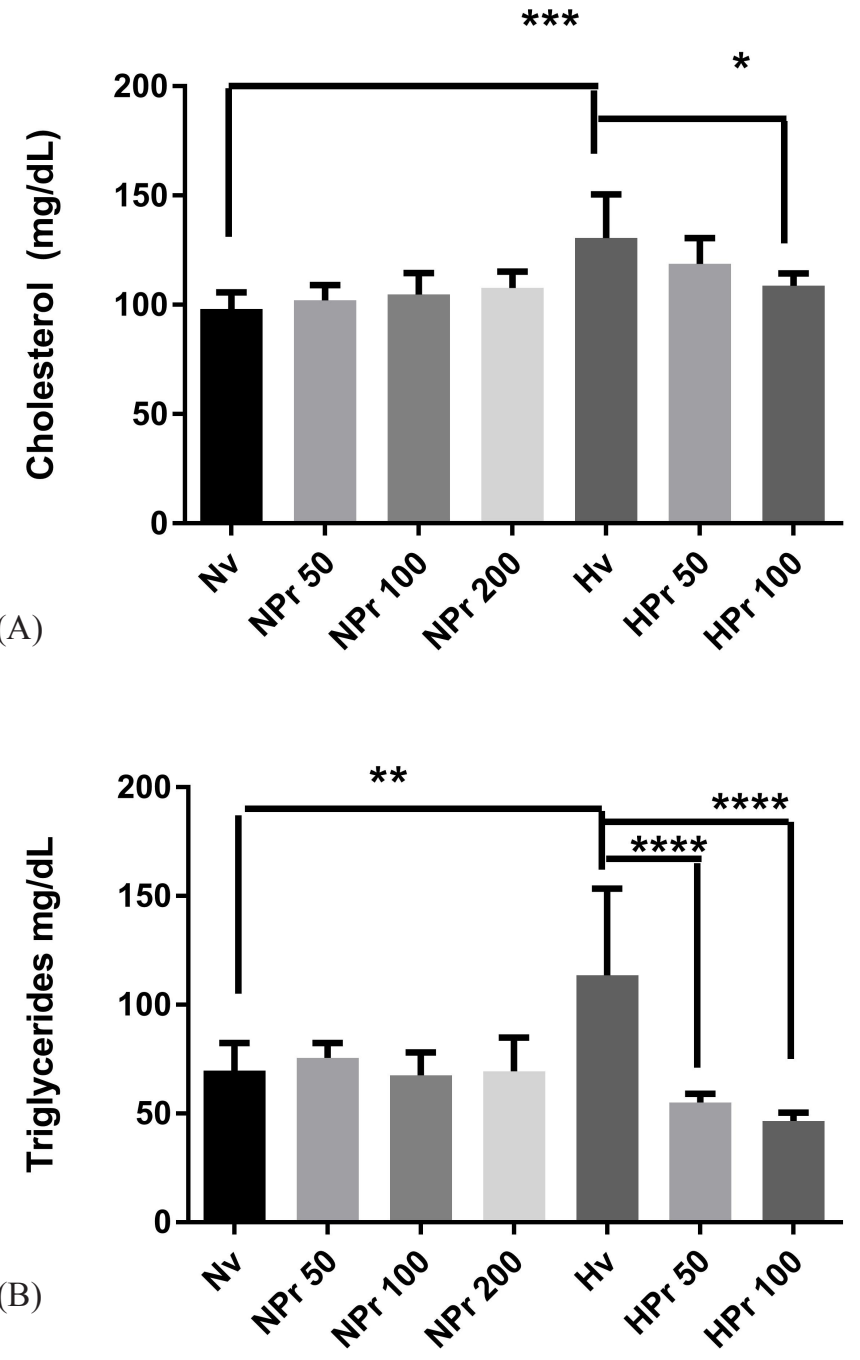

Figure 1: Cholesterol (A) and triglyceride (B) levels after 45 days of oral treatment with $P$. ruscifolia extract in normal and hyperglycemic mice. Data are expressed as mean $\pm \mathrm{SD}$, after one-way ANOVA, Tukey's posttest; * $p<$ $0.1 ; * * p<0.01 ; * * * p<0.001 ; * * * * p<0.0001$.

and HPr 100 groups showed a significant decrease compared to the Hv group (HPr 50: $55.00 \mathrm{mg} / \mathrm{dl} \pm 4.15, p<0.0001$; HPr 100: $46.58 \mathrm{mg} / \mathrm{dl} \pm 3.80, p<0.0001)$ after treatment with the extract of $P$. ruscifolia. This indicated that the extract of $P$. ruscifolia has a lipid-lowering effect in hyperglycemic animals due to alloxan (Fig. 1B).

Regarding HDL-c, the group of hyperglycemic animals treated with the vehicle, $\mathrm{Hv}(31.00 \mathrm{mg} / \mathrm{dl} \pm 2.68)$, presented a difference in the $\mathrm{Nv}$ group $(30.3 \mathrm{mg} / \mathrm{dl} \pm 2.4)$. Interestingly, in the HPr 50 and HPr 100 groups, a significant elevation was observed $(84.1 \mathrm{mg} / \mathrm{dl}$ \pm 10.7 and $32.9 \mathrm{mg} / \mathrm{dl} \pm 5.4$, resp.), so it is presumed with these doses a cardioprotective effect (Fig. 2A).

In the hyperglycemic animals that received the vehicle, the LDL-c level was $72.5 \mathrm{mg} / \mathrm{dl} \pm 10$, significantly different from the $\mathrm{Nv}$ $(61.9 \mathrm{mg} / \mathrm{dl} \pm 8.13)$. Those hyperglycemic animals treated with 

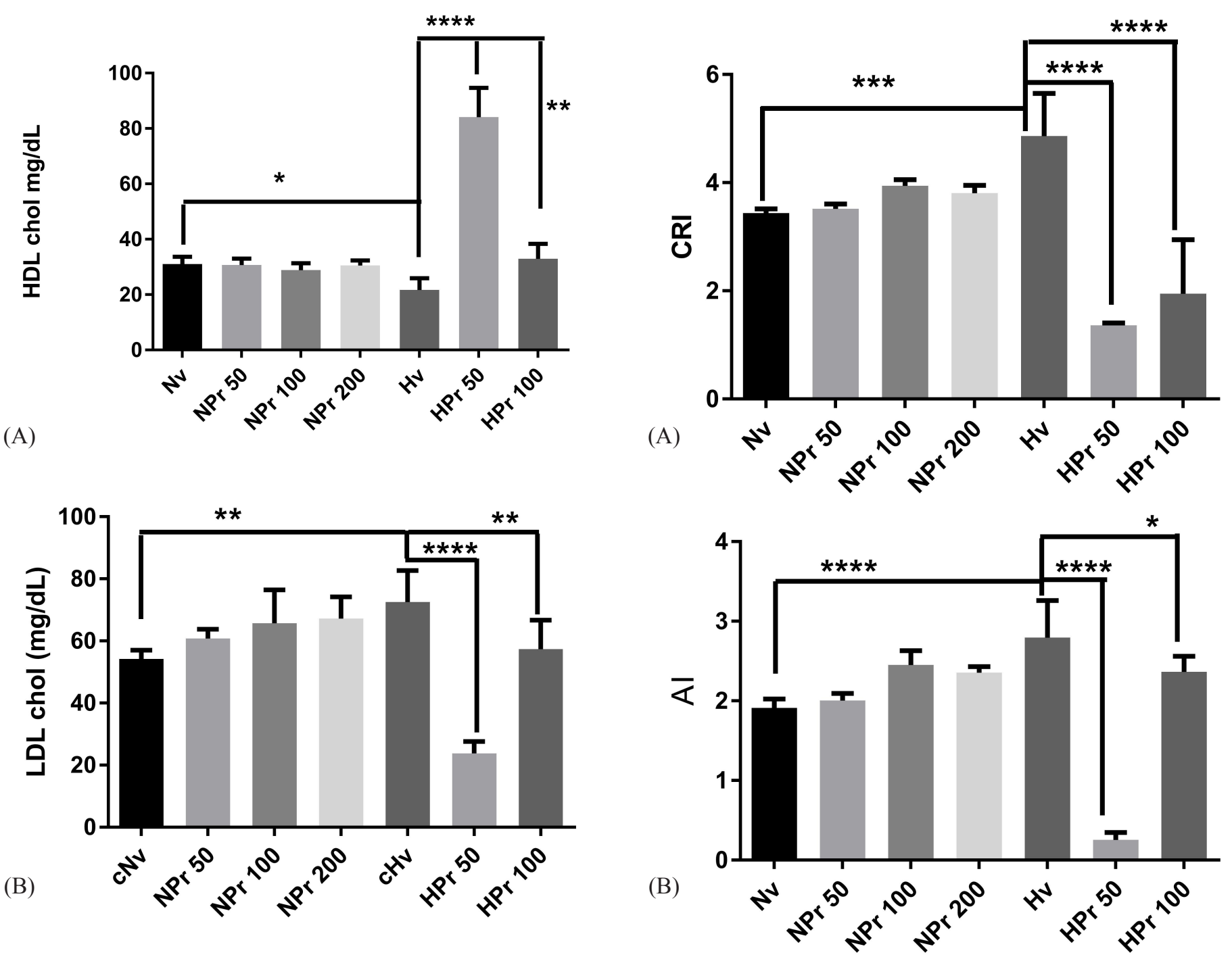

Figure 2: HDL (A) and LDL (B) cholesterol level after 45 days of oral treatment with $P$. ruscifolia extract, in normal and hyperglycemic mice. Data are expressed as mean $\pm \mathrm{SD}$, after one-way ANOVA, Tukey's posttest; ${ }^{*} p<$ $0.1 ; * * p<0.01 ; * * * * p<0.0001$

Figure 3: $\mathrm{CRI}$ (A) and AI (B) after 45 days of oral treatment with P. ruscifolia extract, in normal and hyperglycemic mice. Data are expressed as mean $\pm \mathrm{SD}$, after one-way ANOVA, Tukey's posttest; ${ }^{*} p<0.1 ; * * * p<0.001 ; * * * * p<$ 0.0001 .

the extract of P. ruscifolia $\mathrm{HPr} 50$ and $\mathrm{HPr} 100(23.8 \mathrm{mg} / \mathrm{dl} \pm 3.8$ and $57.3 \mathrm{mg} / \mathrm{dl} \pm 9.3$, resp.) presented a significant decrease in the concentration of cholesterol - LDL (Fig. 2B). In addition, a significant difference was observed in the level of VLDL-c between the groups HPr $100(8.95 \mathrm{mg} / \mathrm{dl} \pm 0.78 p<0.01)$ and $\mathrm{Hv}(13.67 \mathrm{mg} / \mathrm{dl} \pm 2.01)$. Additionally, the CRI and AI were calculated, and the results are shown in Figures 3A and 3B (CRI: HPr $501.36 \pm 0.043$; HPr $1001.95 \pm 0.99$; both $p<0.0001$. AI: HPr $500.26 \pm 0.92, p<0.0001$ and $\operatorname{HPr} 1002.37 \pm 0.195, p<0.1$ ). Both showed a significant reduction, indicating a cardioprotective effect in the animals that were treated with the extract.

\subsection{Effect of P. ruscifolia on the Lipid Profile of Male Mice with Hyperlipidemia Induced by Tyloxapol}

For the evaluation of the effect of the extract of $P$. ruscifolia on the lipid profile of mice, 8 groups of male mice $(n=6)$ were used, and four groups were induced hyperlipidemia with

tyloxapol. Among the animals that were not induced, Nv, NPr 50, NPr 100, and NPr 200, no difference was observed between the lipid profile parameters measured. On the other hand, the animals that were induced to hyperlipidemia with tyloxapol (Hv) presented an elevation in the concentration of cholesterol and triglycerides, compared to the noninduced ones (Table 2). The animals treated with the extract of $P$. ruscifolia had significantly reduced cholesterol level (Hv 50) and triglyceride level. However, between the values, there was no statistically significant difference (Hv 50 and Hv 100), compared to the group without treatment. Between the group of hyperlipidemic mice, Hv, and the normolipemic mice, Nv, no statistically significant difference was found in HDL-c. Nevertheless, the treated animals of the HPr 50 and HPr 200 groups showed a significant increase in this parameter (Table 2). 
Table 2: Effect of P. ruscifolia leaves extract on lipid profile, in tyloxapol-induced hyperlipidemia in male and female mice.

\begin{tabular}{|c|c|c|c|}
\hline \multicolumn{4}{|c|}{ Male } \\
\hline Group & Cholesterol mg/dl & Triglycerides mg/dl & HDL-Chol mg/d \\
\hline $\mathrm{Nv}$ & $97.5 \pm 9.80$ & $77.67 \pm 10.65$ & $24.83 \pm 4.31$ \\
\hline NPr 50 & $105.8 \pm 24.24$ & $97.50 \pm 13.40$ & $25.83 \pm 5.57$ \\
\hline NPr 100 & $108.5 \pm 9.65$ & $93.00 \pm 18.81$ & $24.83 \pm 6.21$ \\
\hline NPr 200 & $114.5 \pm 21.59$ & $81.33 \pm 12.86$ & $23.33 \pm 3.67$ \\
\hline $\mathrm{Hv}$ & $256.5 \pm 116.9 * * * *$ & $1192 \pm 938.5^{*}$ & $28.00 \pm 7.62$ \\
\hline HPr 50 & $146.3 \pm 24.86 *$ & $788.7 \pm 921.8$ & $40.67 \pm 8.94 *$ \\
\hline HPr 100 & $180.0 \pm 79.09$ & $1423 \pm 581.2$ & $31.00 \pm 4.29$ \\
\hline HPr 200 & $230.5 \pm 67.05$ & $883.3 \pm 463.0$ & $39.83 \pm 3.13 *$ \\
\hline \multicolumn{4}{|c|}{ Female } \\
\hline $\mathrm{Nv}$ & $81.00 \pm 9.01$ & $115.8 \pm 51.44$ & $21.00 \pm 1.27$ \\
\hline NPr 50 & $84.50 \pm 8.87$ & $102.5 \pm 38.98$ & $21.50 \pm 3.21$ \\
\hline NPr 100 & $85.17 \pm 11.60$ & $98.33 \pm 40.52$ & $22.00 \pm 6.72$ \\
\hline NPr 200 & $82.50 \pm 6.09$ & $77.17 \pm 30.75$ & $20.33 \pm 1.86$ \\
\hline $\mathrm{Hv}$ & $251.7 \pm 26.89 * * * *$ & $1651 \pm 464.7 * * * *$ & $8.50 \pm 3.08^{* * *}$ \\
\hline HPr 50 & $153.2 \pm 42.47 * *$ & $402.7 \pm 330.5^{* * *}$ & $13.33 \pm 3.93$ \\
\hline HPr 100 & $151.8 \pm 52.57 * *$ & $976.7 \pm 622.1$ & $20.67 \pm 5.76^{* * *}$ \\
\hline HPr 200 & $234.0 \pm 99.96$ & $987.7 \pm 940.9$ & $17.67 \pm 6.12 *$ \\
\hline
\end{tabular}

Hv was compared with Nv; HPr 50, HPr 100, and HP 200 was compared with Hv.

$* p<0.05 ; * * p<0.01 ; * * * p<0.001 ; * * * * p<0.0001$.

\subsection{Effect of $P$. ruscifolia on the Lipid Profile of Female Mice with Hyperlipidemia Induced by Tyloxapol}

As in the male mice, the female mice that were not induced to hyperlipidemia with tyloxapol, Nv, NPr 50, NPr 100, and NPr 200 , did not show changes in any parameters of the lipid profile measured. In this group of female mice, there was a significant elevation of cholesterol and triglyceride levels and a significant decrease in HDL-c (Table 2). After the acute treatment with the extract of P. ruscifolia (HPr 50 and HPr 100), the groups of female mice presented a lower concentration of cholesterol in serum, compared to the Hv group. In the same way, the serum triglyceride concentration was significantly reduced when they were treated with $50 \mathrm{mg} / \mathrm{kg}$, and with the other doses, although a marked difference is observed, it was not significant. Finally, all the hyperlipidemic groups treated with the extract increased the concentration of HDL-c, and a statistically significant difference was demonstrated between the HPr 100 and HPr 200 groups, compared to the untreated group, Hv (Table 2).

Animal models for the study of diabetes and hyperlipidemia have been widely used $[19,20]$. Alloxan produces a diabetogenic effect through two mechanisms, the inhibition of insulin, and the formation of reactive oxygen species, which lead to selectively necrosis of pancreatic beta cells [21]. The nonionic detergent Triton WR-1339, tyloxapol, produces hyperlipidemia because the inhibition of lipoprotein lipase activity $[22,23]$ produces an elevation of plasma VLDL with a rapid decrease in HDL without altering the albumin concentration. In addition, it reduces the activity of liver acyl-Co A cholesterol acyltransferase and two liver enzymes more associated with lipogenesis with dehydrogenase activity, glucose 6-phosphate dehydrogenase and 6-phosphogluconate dehydrogenase. It has also been observed that the lipemia of these animals was elevated, with the presence of lipid vacuoles in the liver tissue, loss of elastic tissue fibers in the aorta, and marked DNA fragmentation in the brain, which indicates that the effect of tyloxapol goes further than just raising lipids concentrations [23,24].

In our study, a marked increase in glycemia was observed in the groups of animals induced with alloxan [21] compared to the noninduced groups and these levels remained high after treatment with $P$. ruscifolia when compared to the control group $\mathrm{Nv}$ (Table 1). In previous works, we have shown that the extract of $P$. ruscifolia leaves has a hypoglycemic effect at 28 days of treatment $[10,11]$. Other researchers demonstrated the hypoglycemic effect of the bark of $P$. cineraria after a treatment period of 45 days [14] and of the leaves after treatment for 12 weeks [15]. It should be noted that previous studies in our research group were carried out with animals with more moderate hyperglycemia and in one of these studies, Wistar rats were used [10,11]. In this work, hyperglycemia was very severe, above $500 \mathrm{mg} / \mathrm{dl}$, and could not be reversed by treatment with the tested extract.

Regarding the effect of chronic treatment with $P$. ruscifolia extract on the lipid profile of normal and hyperglycemic animals, it was observed that animals induced with alloxan had a higher concentration of cholesterol, triglycerides, LDL-c, and a lower concentration of HDL-c in serum than the animals of the control group, Nv. Furthermore, the animals treated with the extract (HPr100) reduced the concentration of cholesterol and VLDL-c in serum compared to the untreated induced animals, Hv. Regarding triglycerides and LDL-c, it was observed that both doses, 50 and $100 \mathrm{mg} / \mathrm{kg}$, presented a significant decrease in the concentration of these parameters and both doses showed a favorable increase 
in the concentration of HDL-c. In a previous study, in which the animals received the treatment with $100 \mathrm{mg} / \mathrm{kg}$ of the extract of $P$. ruscifolia leaves for 28 days, we found that the concentration of both cholesterol and LDL-c decreased, and HDL-c increased, but no effect on triglycerides was observed after 28 days in alloxaninduced hyperglycemic mice [11].

Our results after treatment for 45 days coincide with the findings of other researchers who conducted studies with the steam bark of $P$. cineraria in Swiss albino mice for the same observation period of 45 days [14]. In another study carried out with the leaves of $P$. cineraria in Wistar rats, after 12 weeks of treatment, this same result was obtained [15]. Taking all these results into account, we can affirm that $P$. ruscifolia has lipid-lowering effects in mice with alloxaninduced hyperglycemia, comparable to those found by other groups of researchers. Additionally, the results of this study demonstrated a decrease in coronary and atherogenic risk in the groups treated with the extract, thus showing a cardioprotective effect $[6,25]$.

Additionally, tyloxapol produces hyperlipidemia mainly by inhibiting the activity of lipoprotein lipase [22,23]. As expected, the acute injection of tyloxapol in both male and female mice produced a significant increase in lipid profile parameters [26,27]. In both male and female mice, a decrease in cholesterol and triglycerides was observed, as demonstrated by other authors [28], and in both groups, an increase in HDL-c concentration was observed after treatment with the extract. These results agree with what was observed by our research group in a 28-day model [11].

The results obtained with this study demonstrate that $P$. ruscifolia could be used as an adjunctive treatment to treat dyslipidemia associated with diabetes and dyslipidemia. The mechanism of action by which the components of this plant produce their effect remains to be elucidated. Prosopis ruscifolia has been reported to possess different metabolites such as flavonoids, saponins, and alkaloids. From this group of compounds, quercetin stands out as a flavonoid that has been shown to have favorable effects in diabetic and hyperlipidemia animal models. Quercetin was identified in the extract of $P$. ruscifolia and in other species of the same genus [11,29].

In both diabetic patients and patients with hyperlipidemia, the tissues are exposed to oxidative stress due to the imbalance in the metabolism of both carbohydrates and lipids [30]. Our obtained results, regarding the lipid profile of the animals treated with $P$. ruscifolia, may be explained by a powerful antioxidant effect of the components present in the plant [31] or the hepatoprotective effect of the extract [12] which promotes correct lipid metabolism and both effects could be related to the quercetin content in the extract [11].

Finally, when analyzing males and females in parallel in the hyperlipidemia induction model by tyloxapol, our results indicated a difference between both sexes regarding their respective intrinsic variability. This result is significant because it demonstrates the importance of working with both male and female animals as they display distinct hormonal imbalances [32].

\section{CONCLUSION}

In this study, it was demonstrated that animals with alloxaninduced hyperglycemia constitute a valid model for studying the effect of viñal on glycemia and lipid profile for a period of 45 days, since hyperglycemia was maintained throughout that period. In addition, treatment for 45 days with the ethanolic extract of $P$. ruscifolia improves the lipid profile parameters in animal models with alloxan-induced hyperglycemia and has a cardioprotective effect, since it improves the values of the coronary risk indices and AI. Mice with tyloxapol-induced hyperlipidemia improved lipid profile values, which was verified by a decrease in cholesterol, an increase in HDL-c in males, a decrease in cholesterol and triglyceride, and an increase in HDL-c in females. Finally, a better effect of the extract on the lipid profile in female mice and less variability between measurements was demonstrated.

\section{AUTHORS' CONTRIBUTIONS}

All authors have made a substantial contribution to this work, read the final manuscript, and approved the submission.

\section{ACKNOWLEDGMENTS}

The authors thank Professor R. Degen, from the Department of Botany, Facultad de Ciencias Químicas, for plant collection and identification and Ms Isabelle Wilson and Mr George López for the English language revision.

\section{FUNDING}

This research was fully supported by research grant from Consejo Nacional de Ciencia y Tecnología, CONACYT, Paraguay (PROCIENCIA PINV15-373), and Facultad de Ciencias Químicas, Universidad Nacional de Asunción, Paraguay. JRC carried out part of the work during the master's program (MCQB) supported by CONACYT, Paraguay (PROCIENCIA POSG16-160).

\section{CONFLICTS OF INTEREST}

The authors report no financial or any other conflicts of interest in this work.

\section{ETHICAL APPROVALS}

Ethics Committee of the Facultad de Ciencias Químicas, UNA, and approved (CEI 470/19).

\section{REFERENCES}

1. Diabetes. [cited $2021 \mathrm{Apr}$ 13]. Available from:https://www.who.int/ news-room/fact-sheets/detail/diabetes

2. Forbes JM, Cooper ME. Mechanisms of diabetic complications. Physiol Rev 2013;93(1):137-88.

3. De Vriese A, Verbeuren T, Van de Voorde J, Lameire N, Vanhoutte P. Endothelial dysfunction in diabetes. Br J Pharmacol 2000;130(5):96374.

4. Cho NH, Shaw JE, Karuranga S, Huang Y, da Rocha Fernandes JD, Ohlrogge AW, et al. IDF Diabetes atlas: global estimates of diabetes prevalence for 2017 and projections for 2045. Diabetes Res Clin Pract 2018;138:271-81.

5. Leon BM, Maddox TM. Diabetes and cardiovascular disease: epidemiology, biological mechanisms, treatment recommendations and future research. World J Diabetes 2015;6(13):1246-58.

6. Mooradian A. Dyslipidemia in type 2 diabetes mellitus. Nat Rev Endocrinol 2009;5(3):150-9.

7. Gnudi L, Long DA. Diabetic nephropathy. 1st edition, Springer, New York, NY, 2020. 
8. Adiels M, Olofsson SO, Taskinen MR, Borén J. Overproduction of very low-density lipoproteins is the hallmark of the dyslipidemia in the metabolic syndrome. Arterioscler Thromb Vasc Biol 2008;28(7):122536.

9. Choudhury H, Pandey M, Hua CK, Mun CS, Jing JK, Kong L, et al. An update on natural compounds in the remedy of diabetes mellitus: a systematic review. J Tradit Complement Med 2017;8(3):361-76.

10. Campuzano-Bublitz MA, Ibarrola DA, Hellión-Ibarrola MC, Dölz $\mathrm{JH}$, Kennedy ML. Acute and chronic anti-hyperglycemic effect of Prosopis ruscifolia extract in normoglycemic and alloxan-induced hyperglycemic rats. J App Pharm Sci 2016;6(05):178-84.

11. Campuzano-Bublitz MA, Diarte EMG, Hellión-Ibarrola MC, Ibarrola DA, Alvarenga NL, et al. Effect of Prosopis ruscifolia on lipid profile in alloxan-induced hyperglycemic mice and chemical characterization of alkaloid and flavonoid fractions. J Appl Pharm Sci 2019;9(06):8693.

12. Soverina MS, Campuzano-Bublitz MA, Centurión JR, Galeano AK, Kennedy ML. Preliminary evaluation of hepatoprotective and nephroprotective effects of Prosopis ruscifolia leaf extract in mice. J Appl Pharm Sci 2019;9(12):37-41.

13. Heydari M, Sarir H, Ghiasi SE, Farhangfar H. Effects of Prosopis farcta fruit hydroalcoholic extract on serum concentrations of glucose and lipids in insulin resistance model of rats. Zahedan J Res Med Sci 2018;20(1):e13498.

14. Sharma N, Garg V, Paul A. Antihyperglycemic, antihyperlipidemic and antioxidative potential of Prosopis cineraria bark. Indian J Clin Biochem 2010;25(2):193-200.

15. Sharma D, Singla YP. Evaluation of antihyperglycemic and antihyperlipidemic activity of Prosopis cineraria (Linn.) in wistar rats. J Sci Innov Res. 2013;2(4):751-758.

16. Ferreira J, Sousa D, Dantas M, Fonseca S, Menezes D, Martins A, et al. Effects of Bixa orellana L. seeds on hyperlipidemia. Phytother Res 2012;27(1):144-7.

17. Shaw Dunn J, Mcletchie N. Experimental alloxan diabetes in the rat. Lancet 1943;242(6265):384-7.

18. National Research Council (US) Committee for the Update of the Guide for the Care and Use of Laboratory Animals. Guide for the care and use of laboratory animals. 8th edition, National Academies Press, Washington, DC, 2011.

19. King AJ. The use of animal models in diabetes research. $\mathrm{Br} \mathrm{J}$ Pharmacol 2012;166(3):877-94

20. Pushpa I, Jayachitra J. Hypolipidemic and antioxidant activity of Phoenix dactylifera L. in albino wistar rats. World J Pharm Pharm Sci 2015;4(05):790-8.

21. Lenzen S. The mechanisms of alloxan- and streptozotocin-induced diabetes. Diabetologia 2007;51(2):216-26.
22. Janicki B, Aron S. Effect of Triton WR-1339 on lipoproteins and lipoprotein lipase of Guinea pig plasma. Exp Biol Med 1962;109(3):507-9.

23. Aboul-Enein A, Rahim E, Youssef A, Afify A. The effect of Triton WR-1339 on lipid metabolism in mice. Fette, Seifen, Anstrichmittel 1986;88(6):226-31.

24. Abdou H, Yousef M, Newairy A. Triton WR-1339-induced hyperlipidemia, DNA fragmentation, neurotransmitters inhibition, oxidative damage, histopathological and morphometric changes: the protective role of soybean oil. J Basic Appl Zool 2018;79(51):1-12.

25. Zhu L, Lu Z, Zhu L, Ouyang X, Yang Y, He W, et al. Lipoprotein ratios are better than conventional lipid parameters in predicting coronary heart disease in Chinese Han people. Kardiol Pol 2015;73(10):931-8.

26. Pandit K, Karmarkar SM, Bhagwat AM. Evaluation of antihyperlipidemic activity of Ficus hispida Linn leaves in triton wr1339 (Tyloxapol) induced hyperlipidemia in mice. Int J Pharm Pharm Sci 2011;3:188-91.

27. Bertges LC, Mourâo Jr CA, Souza JB, Coelho Cardoso VA. Hiperlipidemia induzida por Triton WR-1339 (Tyloxapol) em ratos Wistar. Rev Bras Ciénc Méd Saúde 2011;1(1):29-31.

28. Jain P, Surana S. Hypolipidemic activity of Prosopis cineraria L (Druce) fruit extract and molecular modeling study with farnesoid $\mathrm{X}$ receptor (FXR). Trop J Pharm Res 2015;14(9):1621-8.

29. Yan SX, Li X, Sun CD, Chen KS. Hypoglycemic and hypolipidemic effects of quercetin and its glycosides. China J Chin Mater Med 2015;40(23):4560-7.

30. Kaneto H, Kajimoto Y, Miyagawa J, Matsuoka T, Fujitani Y, Umayahara Y, et al. Beneficial effects of antioxidants in diabetes: possible protection of pancreatic beta-cells against glucose toxicity. Diabetes 1999;48(12):2398-406.

31. Zhang M, Swarts S, Yin L, Liu C, Tian Y, Cao Y, et al. Antioxidant properties of quercetin. Adv Exp Med Biol 2011;701:283-9.

32. Shansky R. Are hormones a "female problem" for animal research? Science 2019;364(6443):825-6.

How to cite this article:

Centurión JR, Diarte EMG, Galeano A, Soverina MS, Arrúa W, Kennedy ML, Campuzano-Bublitz MA. Pharmacological evaluation of Prosopis ruscifolia extract on lipid profile in hyperglycemic and hyperlipidemic mice. J Appl Biol Biotech 2021; 9(06):137-143. 